\title{
The efficacy of ankle arthroplasty on motor function recovery in patients with orthopedic ankle injury: a systematic review and meta-analysis
}

\author{
Tian-Hua Tang ${ }^{1}$, Xiao-Gang Miao ${ }^{1}$, Zhi-Yong Shu ${ }^{1}$, Yuan-Hui Li ${ }^{1}$, Ning Jiang ${ }^{1}$, Jin-Quan Chen ${ }^{1}$, \\ Lan-Zhe Yu' ${ }^{1}$, Hua-Jun Wang ${ }^{2}$, Xiao-Fei Zheng ${ }^{2}$
}

${ }^{1}$ Department of Orthopaedics, Zhuhai People's Hospital, Zhuhai Hospital Affiliated with Jinan University, Zhuhai, China; ${ }^{2}$ Department of Orthopedic Surgery and Sports Medicine Center, The First Affiliated Hospital, Jinan University \& The First Clinical College, Jinan University, Guangzhou, China

Contributions: (I) Conception and design: TH Tang, XF Zheng; (II) Administrative support: XG Miao, ZY Shu, YH Li; (III) Provision of study materials or patients: TH Tang, N Jiang, JQ Chen, LZ Yu, HJ Wang; (IV) Collection and assembly of data: XG Miao, ZY Shu, YH Li, N Jiang, JQ Chen, LZ Yu, HJ Wang, XF Zheng; (V) Data analysis and interpretation: All authors; (VI) Manuscript writing: All authors; (VII) Final approval of manuscript: All authors.

Correspondence to: Xiao-Fei Zheng. Department of Orthopedic Surgery and Sports Medicine Center, The First Affiliated Hospital, Jinan University \& The First Clinical College, Jinan University, 613 West HuangPu Avenue, Guangzhou 510632, China. Email: zhengxiaofei12@163.com.

Background: This study analyzed the effects of ankle arthroplasty on the recovery of motor function in patients with orthopedic ankle injury.

Methods: English databases including PubMed, Web of Science, Embase, and the Cochrane Library were searched for randomized controlled trials (RCTs) examining the effects of ankle arthroplasty, ankle replacement, and joint prosthesis on motor function recovery in patients with orthopedic ankle injury. The outcome indicators included the American Orthopedic Foot and Ankle Society (AOFAS) score, the 36-item short form survey (SF-36) score, the Foot and Ankle Ability Measures (FAAM) score, and the visual analog scale (VAS) score. The quality of the included literature was evaluated using the Jadad tool, and meta-analysis of the experimental data was performed using the Review Manager 5.3 software.

Results: A total of 7 articles, including 443 patients, were analyzed. The meta-analysis showed significant improvement in AOFAS scores among patients in the experiment group (who underwent ankle replacement) compared with those in the control group (who did not undergo ankle replacement) [mean difference (MD) $=-41.89,95 \%$ confidence interval (CI): -51.29 to $32.49, \mathrm{Z}=8.73, \mathrm{P}<0.00001]$, VAS scores $(\mathrm{MD}=5.59,95 \%$ CI: 4.84 to 6.34, $Z=14.56, P<0.00001), S F-36$ scores ( $M D=-13.89,95 \% \mathrm{CI}:-26.74$ to $1.04, \mathrm{Z}=2.12, \mathrm{P}=0.03)$, and FAAM scores (MD =-25.78, 95\% CI: -31.27 to $20.29, \mathrm{Z}=9.20, \mathrm{P}<0.00001)$ compared to patients in the control group.

Discussion: Ankle arthroplasty had a positive effect on the quality of life, daily activities, and motor function recovery of patients with orthopedic ankle injuries. While ankle arthroplasty has potential for clinical application, future high-quality, long-term studies with larger samples and more outcome indicators are warranted to verify these results.

Keywords: Ankle arthroplasty; ankle replacement; articular prosthesis; treatment effects

Submitted Dec 02, 2021. Accepted for publication Jan 30, 2022.

doi: 10.21037/apm-21-3871

View this article at: https://dx.doi.org/10.21037/apm-21-3871 


\section{Introduction}

The ankle joint is a typical type of tackle joint. It is composed of the fibula, the joint surface at the lower end of the tibia, and the trochlea of talus. The lower articular surface of the tibia and the inner and outer ankle surfaces jointly form the socket for the talus pulley (joint head). The front of the pulley joint is wide and the back is narrow. When the foot is in dorsiflexion, the wider front part enters the socket and the joint is stable. In plantar flexion, the narrow back of the tackle enters the socket and the ankle is loose and can move laterally, but the ankle is prone to injury at this time. As the lateral malleolus is longer and lower than the medial malleolus, excessive eversion of the talus can be prevented. Therefore, ankle joint injuries often tend to be varus injuries (1-3). In addition to the injury caused by external forces such as sprains, arthritis can be a major source of ankle problems, causing serious pain and psychological pressure to the patient's daily life, as well as economic and nursing burden to the patient's family $(4,5)$. With advances in the development of social medical technology and the gradual improvement of people's requirements for their own quality of life, the treatment of ankle joint disease has attracted much attention.

In patients with advanced ankle arthroplasty, surgery is usually limited to joint fusion and total ankle arthroplasty (TAA). Posttraumatic ankle arthritis differs from other acute joint diseases and accounts for $56 \%$ to $80 \%$ of all ankle injuries. Since the patients are generally young, the survival rate of the implants is an important factor. During the past 15 years, a large number of global literatures have demonstrated that TAA can be an alternative to ankle fusion $(6,7)$. The first generation of ankle replacement prostheses appeared between 1970 to 1985 . During this period, artificial joint replacement of the hips and knees developed rapidly $(8,9)$, and gradually became the dominant surgical method for the treatment of end-stage arthritis. Correspondingly, fusion surgery, with its increased rates of associated complications, became rarer and almost extinct as its shortcomings were being recognized. Inspired by the success of hip and knee arthroplasty, doctors and scientists developed a variety of artificial ankle prostheses (10-12). For patients with advanced ankle arthroplasty, surgery is usually limited to joint fusion and TAA, with other options such as traction joint replacement $(13,14)$ and allograft considered in specific cases. Particularly in Europe, the emergence of a new generation of mobile bearing non-bone cement prostheses has piqued people's interest in TAA.
Ankle fusion surgery is effective and long-lasting, with high patient satisfaction. It has always been the gold standard for the treatment of end-stage ankle arthritis. Ankle fusion can significantly reduce pain and improve function; but complications are still inevitable, including neurovascular injury, poor incision healing, pain caused by internal plants, unequal length of lower limbs, infection, nonunion, stress fractures, and amputation. In addition, fusion of the ankle joint can cause loss of tibiotalar joint activity and abnormal gait. The adjacent joints accelerate degeneration due to increased stress, which may lead to the occurrence of secondary arthritis over time. Compared with ankle joint fusion, ankle joint replacement has the advantages of preserving joint mobility, improving gait, and reducing the load of adjacent joints; and there is no significant difference in pain relief from ankle joint fusion. Disadvantages related to the risk of mechanical complications may require the removal of implants and subsequent joint fusion, which can be technically demanding and lead to less satisfactory results than the initial joint fusion (15). Postoperative function and implant durability are particularly important in effective joint replacement. The main causes of TAA failure are loosening and/or movement of implants, wear, fracture or dislocation of mobile bearings, infection, and unexplained pain (16,17). Therefore, while TAA is rapidly emerging as a suitable alternative to ankle joint erosion, questions remain regarding the long-term functional outcomes, implant survival, and complications.

At present, there are many studies on the effect of ankle joint replacement and ankle fusion on the recovery of motor function of patients with ankle joint injury. However, many clinical studies are concentrated, and there are few articles that systematically analyze and compare the results of these studies. This meta-analysis conducted a systematic analysis of the long-term effects of TAA on functional outcomes and complications in patients with ankle injuries, aiming to provide reference and basis for the clinical treatment of related diseases and the application of related technologies. We present the following article in accordance with the PRISMA reporting checklist (available at https://apm.amegroups.com/article/view/10.21037/apm$21-3871 / \mathrm{rc})$.

\section{Methods}

\section{Literature retrieve}

English databases including PubMed, Web of Science, 
Embase, and The Cochrane Library were searched for related literatures published from January 2000 to September 2020 using the following search terms: "ankle arthroplasty", "joint prosthesis", and "treatment results".

\section{Inclusion and exclusion criteria}

The following inclusion criteria were applied: (I) literature reporting the impact of ankle arthroplasty on the recovery of motor function of patients with orthopedic ankle injuries published at home and abroad; (II) studies that evaluated the motor function recovery of orthopedic ankle arthroplasty patients directly or indirectly; and (III) studies that included at least 15 samples.

The following exclusion criteria were applied: (I) repeat publications of data in the same group; (II) review articles, conference reports, empirical lectures, case reports, and comments; (III) studies unrelated to this research topic; (IV) studies with no control group, or the samples between groups were not comparable; and (V) studies with unclear outcome indicators and incomplete results and data.

\section{Literature quality evaluation}

Two researchers read the full text of the literature and extracted relevant information. Any disagreements or disputes were resolved through discussion or consultation with a third researcher. The Jadad score was used to evaluate the quality of the included literature, including: (I) whether the literature was a randomized controlled trial (RCT); (II) whether the random method used was appropriate; (III) whether the literature was double-blinded; (IV) whether the double-blinded method was appropriate; and (V) whether patients were lost to follow-up or dropped out during the study, whether the reasons were explained, and whether the literature adopted an intentional analysis method. An answer of "Yes" to the above counted as 1 point, and "No" counted as 0 points. Literatures with a score of less than 2 point out of a possible 5 points were considered low quality research. Literatures with a score of more than 2 points was considered high quality research.

The Cochrane Reviewer's Handbook4.2.5 was used to evaluate the literature quality. The evaluation included: (I) whether it was an RCT; (II) whether allocation concealment was adopted; (III) whether a blinded method was used; (IV) whether the result data was complete; (V) whether there was selective reporting of results; and (VI) whether there were other biases.

\section{Data extraction}

The following data were collated: (I) the general characteristics of the literature including first author, publication year, evaluation results, and other data; (II) the evaluation results including the number of research subjects, experimental design, specific measures, research time, and outcome indicators; (III) the baseline data of the patients; and (IV) the indicators of research quality.

\section{Statistical analysis}

Data were statistically analyzed using the Revman5.3 software provided by the Cochrane collaboration. Heterogeneity tests were performed on the experimental results using $\alpha=0.05$ as the cutoff. The Peto method was used for literature heterogeneity analysis. When $\mathrm{I}^{2}<50 \%$, it was considered that there was no heterogeneity in the literature and the fixed effects model (FEM) was used for analysis. When $\mathrm{I}^{2}>50 \%$, it was considered that there was heterogeneity, and the random effects model (REM) was used for analysis. Among the measurement data results, weighted mean difference (WMD) was used for the results using the same unit of measure, otherwise, standard mean difference (SD) was used. The results of counting data were expressed by relative risk (RR). All results were expressed using $95 \%$ confidence intervals (CI). Funnel plots were drawn and publication bias was assessed using the symmetry of the funnel plot and the centralization of literature towards the midline. Sensitivity analysis was used to assess the reliability and stability of the results.

\section{Results}

\section{Literature retrieval results}

A total of 618 records were retrieved from the databases, and 226 publications related to this study were obtained after duplicates were deleted. After reading the abstracts and titles of the articles, 26 documents that satisfied the selection criteria were identified. Finally, after a review of the full text, 7 literatures were included in this study (18-24). The literature retrieval process is shown in Figure 1 and the basic information of the included literature is shown in Table 1.

\section{Bias risk assessment of included literature}

The quality of the included literature was first evaluated 


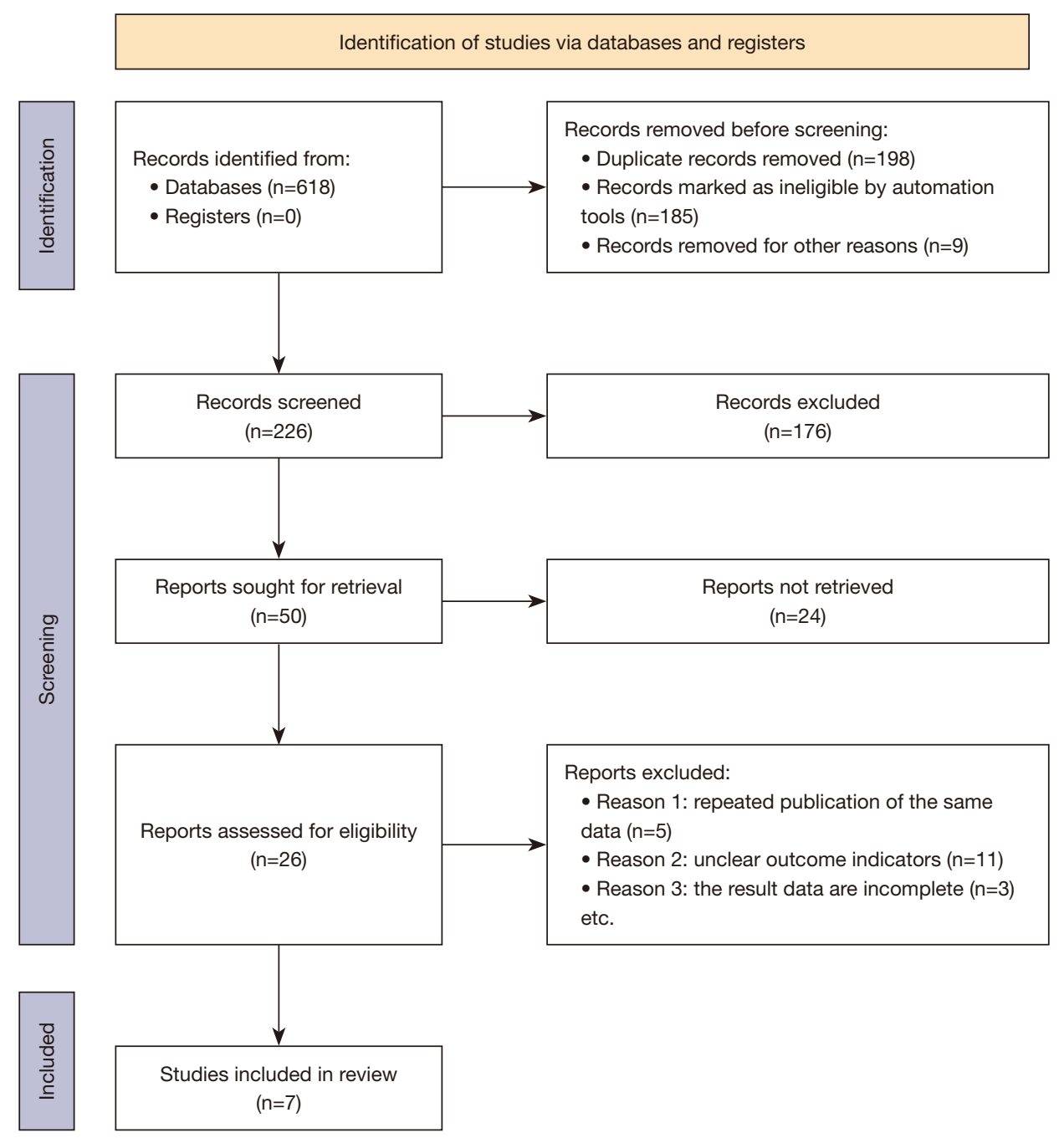

Figure 1 A flowchart showing the literature retrieve process.

Table 1 The basic characteristics of the included literature

\begin{tabular}{|c|c|c|c|c|}
\hline First author & Year of publication & Outcome indicators & Test & Control \\
\hline Braito M (18) & 2014 & AOFAS, VAS & 101 & 40 \\
\hline Esparragoza L (19) & 2011 & AOFAS, SF-36 & 14 & 16 \\
\hline Dalat F (20) & 2014 & AOFAS, SF-36, FAAM & 59 & 46 \\
\hline Brunner S (21) & 2013 & AOFAS, VAS & 72 & 72 \\
\hline Pedowitz DI (23) & 2016 & VAS, FAAM & 41 & 27 \\
\hline Veljkovic AN (24) & 2019 & SF-36 & 88 & 50 \\
\hline
\end{tabular}

AOFAS, American Orthopedic Foot and Ankle Society; VAS, visual analogue scale; SF-36, 36-item short form survey; FAAM, Foot and Ankle Ability Measures. 


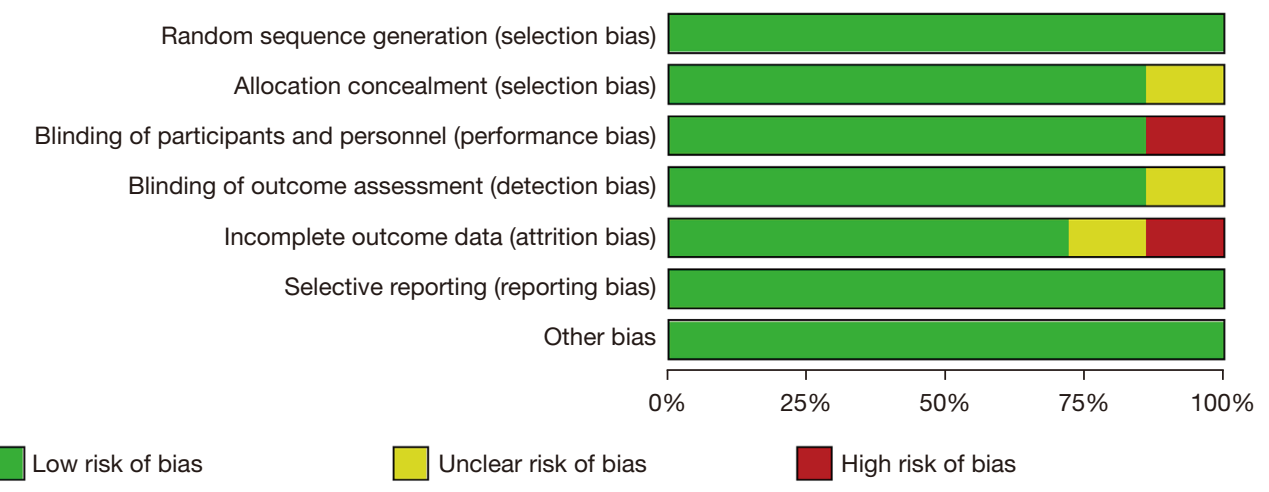

Figure 2 A bar chart showing the bias risk assessment of the included literature.

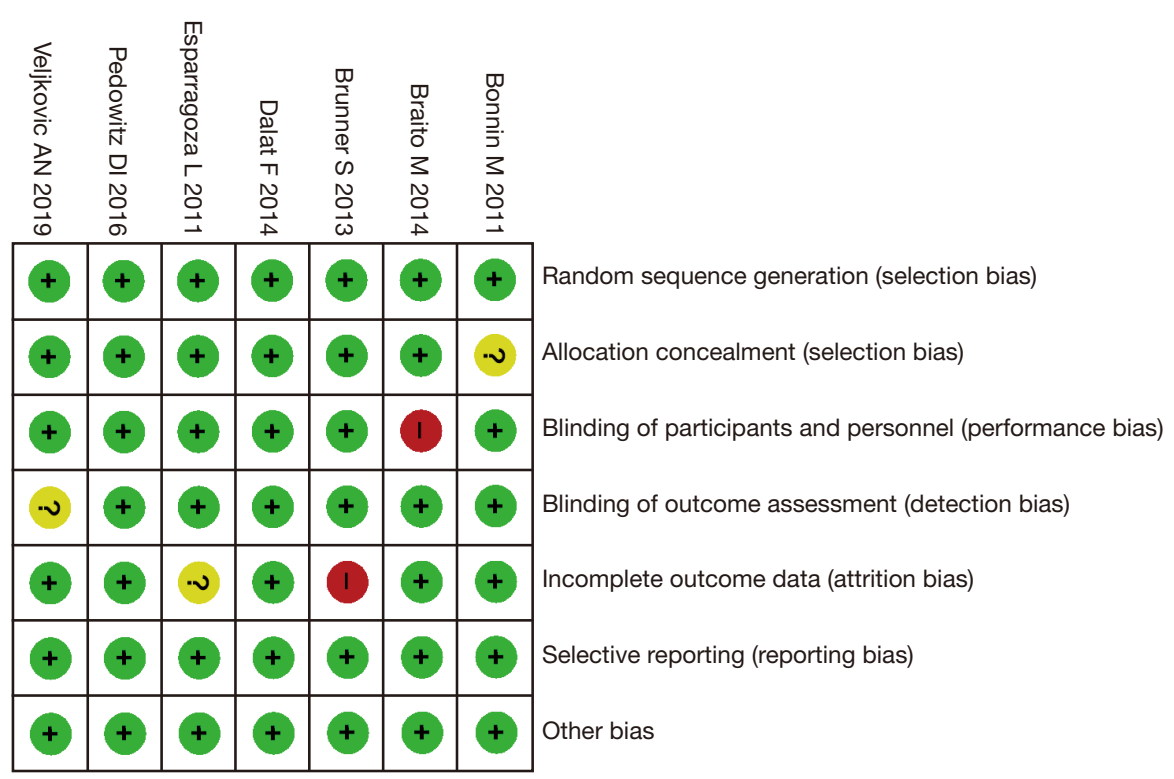

Figure 3 The risk assessment of bias in the included literature.

using the bias risk assessment tool recommended by the Cochrane Systematic Review Manual, and the results are shown in Figure 2 and Figure 3. Random sequence generation (selection bias), incomplete outcome data (selection bias), and selective reporting were not present in any of the 7 studies (reporting bias). Overall, the risks included in this study were low.

The Jadad scale was used to evaluate the quality of each included literature, and the results are shown in Table 2. All 7 articles included in the study had low risk of bias and satisfied the requirements of subsequent analyses.
Meta-analysis of the American Orthopedic Foot and Ankle Society (AOFAS) score in patients after ankle artbroplasty

In the included literature, 5 studies described in detail the AOFAS scores of patients after ankle arthroplasty (Figure 4). There was significant heterogeneity in the AOFAS scores of patients in the control group (who did not undergo ankle replacement) and the experimental group (who underwent ankle replacement) $\left(\mathrm{I}^{2}=95 \%, \mathrm{P}<0.00001\right)$ and the REM was used for statistical analysis. The AOFAS scores of patients who underwent ankle arthroplasty were significantly 
Table 2 The Jadad scale for quality assessment of the included literature

\begin{tabular}{|c|c|c|c|c|c|c|}
\hline First author & Randomization & Binding & Allocation concealment & Withdrawals and dropouts & $\begin{array}{l}\text { Reason for dropouts } \\
\text { and withdrawals }\end{array}$ & Jadad \\
\hline Braito M (18) & Yes & No & NMT & MT & No & 5 \\
\hline Esparragoza L (19) & Yes & No & NMT & MT & Yes & 3 \\
\hline Dalat F (20) & Yes & No & NMT & MT & Yes & 3 \\
\hline Pedowitz DI (23) & Yes & No & NMT & MT & No & 4 \\
\hline Veljkovic AN (24) & Yes & No & NMT & MT & No & 4 \\
\hline
\end{tabular}

MT, mentioned; NMT, not mentioned.



Figure 4 Forest plot of American Orthopedic Foot and Ankle score (AOFAS) comparison between experimental group and control group.

different to the scores of control patients (who did not undergo ankle replacement) ( $M D=-41.89,95 \%$ CI: -51.29 to $-32.49, \mathrm{Z}=8.73, \mathrm{P}<0.00001)$.

\section{Meta-analysis of the visual analogue scale (VAS) score in patients after ankle artbroplasty}

In the included literature, 3 studies evaluated the VAS scores of patients after ankle arthroplasty (Figure 5). There was significant heterogeneity in the VAS scores of the control group and the experimental group $\left(\mathrm{I}^{2}=52 \%, \mathrm{P}=0.12\right)$ and the REM was used. Meta-analysis revealed that the VAS scores were significantly different between patients who underwent ankle arthroplasty and those who did not ( $M D=5.59,95 \%$ CI: 4.84 to $6.34, Z=14.56, P<0.00001)$.

\section{Meta-analysis of the 36-item short form survey (SF-36) score in patients after ankle arthroplasty}

In the included literature, 3 studies examined the SF-36 scores of patients after ankle arthroplasty (Figure 6). There was significant heterogeneity in the SF-36 scores of the control group and the experimental group $\left(\mathrm{I}^{2}=97 \%, \mathrm{P}<0.00001\right)$ and the REM was used. Meta-analysis showed that the SF36 scores were significantly different between patients who had undergone ankle arthroplasty and control patients ( $M D=-13.89,95 \%$ CI: -26.74 to $-1.04, Z=2.12, P=0.03)$.

\section{Meta-analysis of the Foot and Ankle Ability Measures (FAAM) score in patients after ankle arthroplasty}

In the included literature, 2 studies detailed the FAAM scores of patients after ankle arthroplasty (Figure 7). There was no significant heterogeneity in the FAAM scores between the control group and the experimental group $\left(\mathrm{I}^{2}=0 \%, \mathrm{P}=0.61\right)$ and the FEM was used for statistical analysis. The results revealed that the FAAM scores were significantly different between ankle arthroplasty patients and control patients $(\mathrm{MD}=-25.78,95 \% \mathrm{CI}:-31.27$ to $-20.29, Z=9.20, P<0.00001)$.

\section{Publication bias analysis}

The publication bias of the AOFAS score, SF-36 score, 


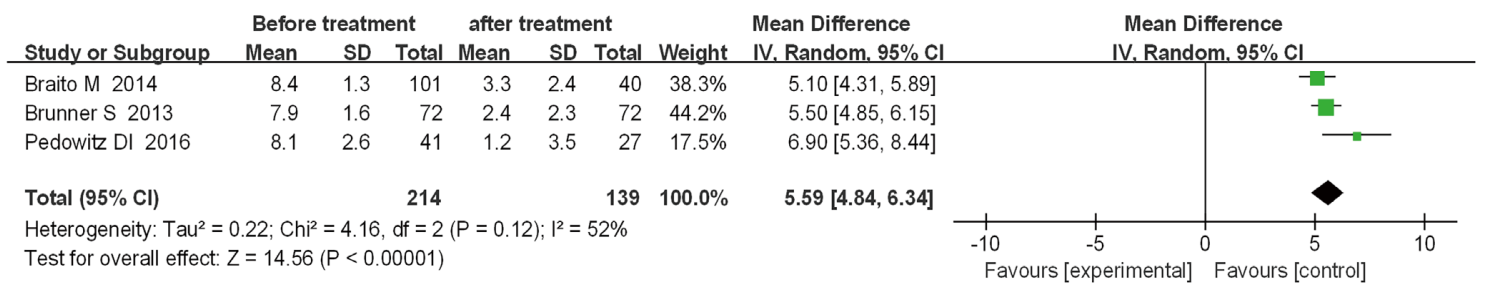

Figure 5 A forest map showing the visual analogue scale (VAS) scores after ankle arthroplasty.

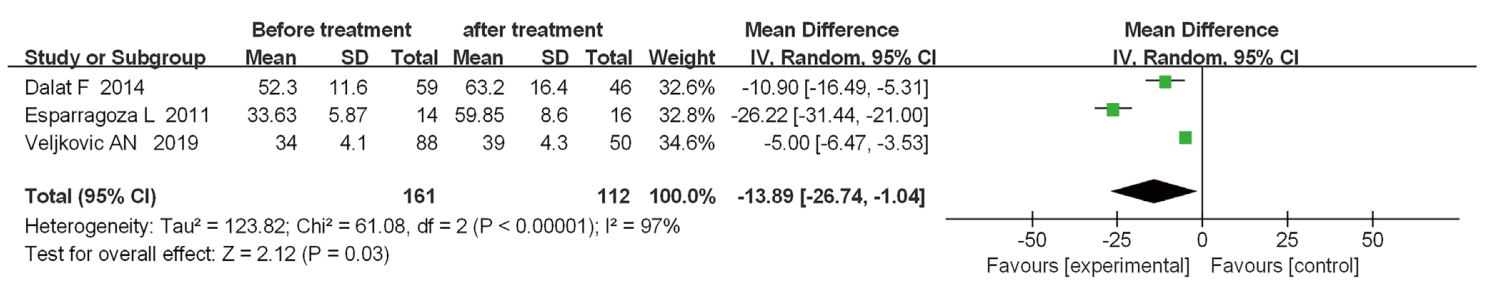

Figure $6 \mathrm{~A}$ forest map showing the 36-item short form survey (SF-36) scores in patients after ankle arthroplasty.



Figure 7 A forest map showing the Foot and Ankle Ability Measures (FAAM) scores in patients after ankle arthroplasty.

FAAM score, and VAS score was analyzed (Figure 8). The funnel plots were symmetrical and the data were concentrated, indicating that none of the four functional indexes included in this study had significant publication bias.

\section{Discussion}

Ankle arthroplasty is a type of artificial joint replacement for the treatment of ankle diseases. The main purpose is to provide patients with a more stable and functional ankle joint. The replaced ankle prostheses generally require good soft tissue tension and non-collision range of motion (25). This joint replacement can effectively improve the symptoms of joint pain in patients.

To analyze the impact of ankle arthroplasty on functional recovery in patients with ankle injuries, this study included the AOFAS score as an evaluation indicator. Although the AOFAS score is not a scoring system specifically validating ankle arthroplasty, it is the most commonly used clinical outcome score in foot and ankle surgery since 1994 (26,27). The AOFAS score has also been shown to be sufficient to evaluate the postoperative improvement of patients with TAA. There were significant differences in AOFAS scores between the experimental group and the control group at the same time. It is worth noting that some studies showed a gradual decrease in AOFAS score during longer followup periods. There are two possible reasons for the gradual decline in AOFAS scores $(28,29)$. First, long-term wear of the polyethylene lining and sinking and loosening of the prosthesis can lead to reduced ankle function. In addition, issues related to stability, pain, or the development of heterotopic ossification may develop over time, leading to a decline in clinical outcome scores. However, the decline in AOFAS scores was not widespread during the long followup period.

The survival rate of ankle implants was not included in our investigation, although this is an important outcome 

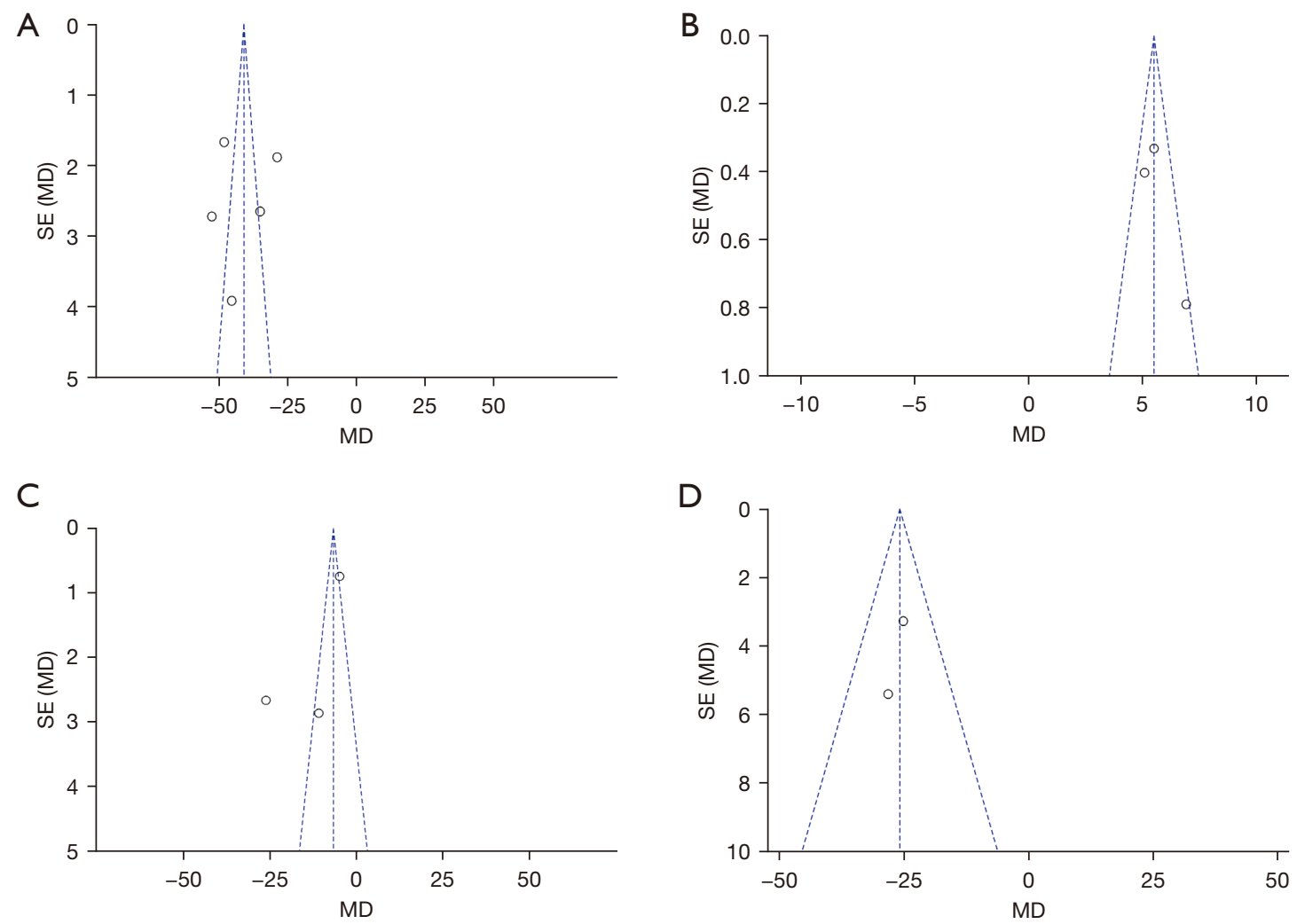

Figure 8 Funnel plots of the related indicators, including (A) the American Orthopedic Foot and Ankle Society (AOFAS) score; (B) the visual analogue scale (VAS) score; (C) the 36-item short form survey (SF-36) score; and (D) the Foot and Ankle Ability Measures (FAAM) score. SE, standard error; MD, mean difference.

measure in ankle arthroplasty. Restoration surgery may lead to additional risks of infection, morbidity, and mortality, as well as further hospitalization and rehabilitation (30). All these impose a significant burden on health systems and the social economy. Data vary widely from country to country, including a 5 -year survival rate of $83 \%$ reported by the Finnish Arthroplasty Registry ( $\mathrm{n}=515)$, a 7 -year survival rate of $91.3 \%$ reported by the National Joint Registry of England, Wales, and Northern Ireland $(n=4,687)$, an 11-year survival rate of $79.5 \%$ reported by the New Zealand Joint Registry $(\mathrm{n}=1,380)$, and a 10 -year survival rate of $69 \%$ reported by the Swedish Ankle Registry ( $\mathrm{n}=780$ ) (31). Therefore, these data were not included in our analysis to avoid errors due to regional differences and different data collection methods.

Since the present study was a systematic review of prospective and retrospective studies, there was heterogeneity in the data regarding surgery, implant design, and surgical technique. Therefore, there may be some differences in the results, which were minimized in this study. Moreover, the indicators examined in this report were limited and future studies assessing other indicators should be conducted to verify these results.

\section{Conclusions}

In this meta-analysis, a total of 7 suitable articles, involving 443 patients, were selected. The quality of the included literature was evaluated using the Jadad tool and metaanalysis of the experimental data was performed using the Review Manager 5.3 software. Meta-analysis showed significant differences in preoperative and postoperative AOFAS scores, VAS scores, SF-36 scores, and FAAM scores between the experimental group (who underwent ankle replacement) and the control group (who didn't receive ankle replacement). In conclusion, ankle arthroplasty has a positive effect on the recovery of motor function, quality of life, and daily activities in patients with orthopedic 
ankle injuries. Future studies involving higher-quality research, larger sample sizes, and more outcome indicators was warranted to verify the clinical application of ankle arthroplasty.

\section{Acknowledgments}

Funding: None.

\section{Footnote}

Reporting Checklist: The authors have completed the PRISMA reporting checklist. Available at https://apm. amegroups.com/article/view/10.21037/apm-21-3871/rc

Conflicts of Interest: All authors have completed the ICMJE uniform disclosure form (available at https://apm. amegroups.com/article/view/10.21037/apm-21-3871/coif). The authors have no conflicts of interest to declare.

Ethical Statement: The authors are accountable for all aspects of the work in ensuring that questions related to the accuracy or integrity of any part of the work are appropriately investigated and resolved.

Open Access Statement: This is an Open Access article distributed in accordance with the Creative Commons Attribution-NonCommercial-NoDerivs 4.0 International License (CC BY-NC-ND 4.0), which permits the noncommercial replication and distribution of the article with the strict proviso that no changes or edits are made and the original work is properly cited (including links to both the formal publication through the relevant DOI and the license). See: https://creativecommons.org/licenses/by-nc-nd/4.0/.

\section{References}

1. Hertel J, Corbett RO. An Updated Model of Chronic Ankle Instability. J Athl Train 2019;54:572-88.

2. Vancolen SY, Nadeem I, Horner NS, et al. Return to Sport After Ankle Syndesmotic Injury: A Systematic Review. Sports Health 2019;11:116-22.

3. Panagiotakis E, Mok KM, Fong DT, et al. Biomechanical analysis of ankle ligamentous sprain injury cases from televised basketball games: Understanding when, how and why ligament failure occurs. J Sci Med Sport 2017;20:1057-61.

4. Bessis N, Decker P, Assier E, et al. Arthritis models: usefulness and interpretation. Semin Immunopathol 2017;39:469-86.

5. Verhoeven F, Tordi N, Prati C, et al. Physical activity in patients with rheumatoid arthritis. Joint Bone Spine 2016;83:265-70.

6. Liu X, Zhang H, Li Y, et al. Application of Negative Pressure Wound Therapy in Total Ankle Replacement. J Foot Ankle Surg 2021;60:283-7.

7. Usuelli FG, Indino C, Maccario C, et al. A Modification of the Fibular Osteotomy for Total Ankle Replacement Through the Lateral Transfibular Approach. J Bone Joint Surg Am 2019;101:2026-35.

8. L Snell D, Hipango J, Sinnott KA, et al. Rehabilitation after total joint replacement: a scoping study. Disabil Rehabil 2018;40:1718-31.

9. Kwong LM, Kimball JA. Postorthopedic Surgery Joint Replacement Surgery Venous Thromboembolism Prophylaxis. Hematol Oncol Clin North Am 2016;30:1007-18.

10. Rogers EA, Carney ME, Yeon SH, et al. An Ankle-Foot Prosthesis for Rock Climbing Augmentation. IEEE Trans Neural Syst Rehabil Eng 2021;29:41-51.

11. Schlafly M, Reed KB. Novel passive ankle-foot prosthesis mimics able-bodied ankle angles and ground reaction forces. Clin Biomech (Bristol, Avon) 2020;72:202-10.

12. Fylstra BL, Lee IC, Huang S, et al. Human-prosthesis coordination: A preliminary study exploring coordination with a powered ankle-foot prosthesis. Clin Biomech (Bristol, Avon) 2020;80:105171.

13. Southworth TM, Naveen NB, Tauro TM, et al. The Use of Platelet-Rich Plasma in Symptomatic Knee Osteoarthritis. J Knee Surg 2019;32:37-45.

14. Ball CM. Neurologic complications of shoulder joint replacement. J Shoulder Elbow Surg 2017;26:2125-32.

15. Egrise F, Parot J, Bauer C, et al. Complications and results of the arthrodesis after total ankle arthroplasty failure: a retrospective monocentric study of 12 cases. Eur J Orthop Surg Traumatol 2020;30:373-81.

16. Li SY, Myerson MS. Management of Talar Component Subsidence. Foot Ankle Clin 2017;22:361-89.

17. Othman S, Colen DL, Azoury SC, et al. Soft-Tissue Reconstruction of Complicated Total Ankle Arthroplasty. Foot Ankle Spec 2020. [Epub ahead of print].

18. Braito M, Dammerer D, Kaufmann G, et al. Are our expectations bigger than the results we achieve? a comparative study analysing potential advantages of ankle arthroplasty over arthrodesis. Int Orthop 2014;38:1647-53. 
19. Esparragoza L, Vidal C, Vaquero J. Comparative study of the quality of life between arthrodesis and total arthroplasty substitution of the ankle. J Foot Ankle Surg 2011;50:383-7.

20. Dalat F, Trouillet F, Fessy MH, et al. Comparison of quality of life following total ankle arthroplasty and ankle arthrodesis: Retrospective study of 54 cases. Orthop Traumatol Surg Res 2014;100:761-6.

21. Brunner S, Barg A, Knupp M, et al. The Scandinavian total ankle replacement: long-term, eleven to fifteenyear, survivorship analysis of the prosthesis in seventy-two consecutive patients. J Bone Joint Surg Am 2013;95:711-8.

22. Bonnin M, Gaudot F, Laurent JR, et al. The Salto total ankle arthroplasty: survivorship and analysis of failures at 7 to 11 years. Clin Orthop Relat Res 2011;469:225-36.

23. Pedowitz DI, Kane JM, Smith GM, et al. Total ankle arthroplasty versus ankle arthrodesis: a comparative analysis of arc of movement and functional outcomes. Bone Joint J 2016;98-B:634-40.

24. Veljkovic AN, Daniels TR, Glazebrook MA, et al. Outcomes of Total Ankle Replacement, Arthroscopic Ankle Arthrodesis, and Open Ankle Arthrodesis for Isolated Non-Deformed End-Stage Ankle Arthritis. J Bone Joint Surg Am 2019;101:1523-9.

25. Lawton CD, Butler BA, Dekker RG 2nd, et al. Total ankle arthroplasty versus ankle arthrodesis-a comparison of outcomes over the last decade. J Orthop Surg Res

Cite this article as: Tang TH, Miao XG, Shu ZY, Li YH, Jiang N, Chen JQ, Yu LZ, Wang HJ, Zheng XF. The efficacy of ankle arthroplasty on motor function recovery in patients with orthopedic ankle injury: a systematic review and meta-analysis. Ann Palliat Med 2022;11(2):621-630. doi: 10.21037/apm-21-3871
2017;12:76.

26. Bemenderfer TB, Davis WH, Anderson RB, et al. Heterotopic Ossification in Total Ankle Arthroplasty: Case Series and Systematic Review. J Foot Ankle Surg 2020;59:716-21.

27. Shih CL, Chen SJ, Huang PJ. Clinical Outcomes of Total Ankle Arthroplasty Versus Ankle Arthrodesis for the Treatment of End-Stage Ankle Arthritis in the Last Decade: a Systematic Review and Meta-analysis. J Foot Ankle Surg 2020;59:1032-9.

28. Sun Z, Chen Y, Zhang H, et al. Application of anatomical approach osteoligaments repair technique in treatment of pronation ankle fractures. Zhongguo Xiu Fu Chong Jian Wai Ke Za Zhi 2019;33:1351-7.

29. Amani A, Shakeri V, Kamali A. Comparison of calcaneus joint internal and external fractures in open surgery and minimal invasive methods in patients. Eur J Transl Myol 2018;28:7352.

30. Undén A, Jehpsson L, Kamrad I, et al. Better implant survival with modern ankle prosthetic designs: 1,226 total ankle prostheses followed for up to 20 years in the Swedish Ankle Registry. Acta Orthop 2020;91:191-6.

31. Usuelli FG, Di Silvestri CA, D'Ambrosi R, et al. Total ankle replacement: is pre-operative varus deformity a predictor of poor survival rate and clinical and radiological outcomes? Int Orthop 2019;43:243-9. 